IZA DP No. 4475

Oportunidades: Program Effect on Consumption, Low Participation, and Methodological Issues

Manuela Angelucci

Orazio Attanasio

October 2009 


\title{
Oportunidades: Program Effect on Consumption, Low Participation, and Methodological Issues
}

\author{
Manuela Angelucci \\ University of Arizona and IZA \\ Orazio Attanasio \\ University College London, \\ BREAD, CEPR, IFS and NBER
}

Discussion Paper No. 4475

October 2009

\author{
IZA \\ P.O. Box 7240 \\ 53072 Bonn \\ Germany \\ Phone: +49-228-3894-0 \\ Fax: +49-228-3894-180 \\ E-mail: iza@iza.org
}

\begin{abstract}
Any opinions expressed here are those of the author(s) and not those of IZA. Research published in this series may include views on policy, but the institute itself takes no institutional policy positions.

The Institute for the Study of Labor (IZA) in Bonn is a local and virtual international research center and a place of communication between science, politics and business. IZA is an independent nonprofit organization supported by Deutsche Post Foundation. The center is associated with the University of Bonn and offers a stimulating research environment through its international network, workshops and conferences, data service, project support, research visits and doctoral program. IZA engages in (i) original and internationally competitive research in all fields of labor economics, (ii) development of policy concepts, and (iii) dissemination of research results and concepts to the interested public.
\end{abstract}

IZA Discussion Papers often represent preliminary work and are circulated to encourage discussion. Citation of such a paper should account for its provisional character. A revised version may be available directly from the author. 
IZA Discussion Paper No. 4475

October 2009

\section{ABSTRACT}

\section{Oportunidades: Program Effect on Consumption, Low Participation, and Methodological Issues ${ }^{\star}$}

In this paper we estimate the effect of the Mexican conditional cash transfer program, Oportunidades, on consumption, and we explore some issues related to participation to the program and to the estimation of treatment effects. We discuss the comparability of treatment and control areas, provide evidence that the expected transfer may not be sufficiently high to induce many eligible households to participate, and find positive effects on consumption.

JEL Classification: D12, O12

Keywords: $\quad$ program evaluation, consumption, matching, Oportunidades

Corresponding author:

Manuela Angelucci

Economics Department

University of Arizona

1130 E. Helen St., McClelland Hall 401

Tucson, AZ 85721

USA

E-mail: angelucm@eller.arizona.edu

* Several staff at Oportunidades were very helpful with questions about the details of the data. We are also grateful to Joseph Cullen. 


\section{Introduction}

Conditional cash transfers programs are becoming increasingly popular both in developing and developed countries. While their effects on school enrollment, academic achievement, nutritional and health status of children have been studied extensively, their impact on consumption has received slightly less attention, although some studies now address that issue (see Hoddinot and Skoufias 2003 and Gertler, Martinez and Rubio 2006). Yet, the study of consumption can be very useful for several reasons. First, a presumption of the conditional cash transfers, as an alternative to transfers in kind, is that poor households have better information on the most profitable activities in which to invest. ${ }^{1}$ Thus, it is important to check what happens to the beneficiaries' budget after they receive a transfer and how they allocate the transfer between different activities. Consumption (and its structure) is obviously an important part of the story here. Second, when the estimation of the impact effects cannot rely on a randomized trial and is based instead on quasi-experimental methods, such as difference-in-difference and matching, the consumption results can be used as an important indirect diagnostic of the assumptions employed by these methods. We can put reasonable bounds on the short run effects of the grant on consumption. It is unlikely, for instance, that poor households increase their consumption by an amount substantially larger than the amount of the grant, at least in the short run. It is also unlikely that the same poor households save a very large fraction of the grant. By comparing the results one obtains with these priors, one can judge the plausibility of the methodology employed in estimating a variety of impacts.

This paper studies the effect of the urban component of Oportunidades on the consumption of beneficiary households. To estimate this impact we have to tackle a number of methodological problems. First and foremost, unlike the rural component of the program, previously known as PROGRESA, the allocation of Oportunidades across urban areas was not random. We therefore

\footnotetext{
${ }^{1}$ The imposition of conditionalities, however, moderates this assertion.
} 
use a combination of difference in difference matching and instrumental variable estimators. We discuss at length the plausibility of the assumptions employed and the problem that the data present in this respect. Second, the take up of the program in urban areas was, relatively to the rural component, quite low: about $50 \%$ of the eligible households registered for the program. The limited participation drives a wedge between the Average Intent to Treat (AIT), which is the effect on the eligible population irrespective of whether they participate to the program, and the Average Treatment on the Treated (ATT). Exploring the determinants of participation is also interesting in its own right. Therefore, we discuss some key correlates of program take-up, showing that participation is strongly correlated with poverty status and it is higher among families with children who were already attending school before the beginning of the program.

We find that households spend about $80 \%$ of the transfer, that they use it primarily to purchase more food, and that the amount consumed increases over time. These results are similar to the findings from the rural component of the program.

\section{Oportunidades: program and data characteristics}

The Oportunidades program, then named PROGRESA, started in 1998 in rural Mexico. In 2003, the program was expanded to urban areas. The urban program differed from its rural counterpart in two important ways: first, in the targeting and registration of beneficiary households, and second, in the design of the evaluation. In the rural localities targeted by PROGRESA, each households knew its eligibility status before the beginning of the program. Subsequently, the take up rate was around $97 \%$. In urban areas, instead, the program operated setting up registration offices (módulos) within eligible areas, and investing resources in spreading the news about the availability of the program in that area. Potential beneficiaries had to visit a local office first, and then found out whether they qualified for the program, based on an estimated poverty status. The consequence of this scheme was that, at least in the 
first two years of operation, many potentially eligible households did not apply for the program - possibly because they were not aware of its existence, or because of uncertainty over their eligibility status, or because Oportunidades was simply less attractive in urban areas than rural areas. Indeed, administrative data indicate that the program take-up is approximately $50 \%$.

As for the evaluation, the rural component used the gradual expansion of the program to set up a randomized trial. A representative sample of 506 villages was drawn. In 320 randomly selected localities the program started in 1998, while in the remaining 186 , the program would not start until the end of 1999. In urban areas, the expansion of the program was not random, but had the following procedure. The unit of analysis was the "manzana", or city block. First, the administration decided to initially offer the program in the blocks with the highest density of poor households. It selected the poorest blocks using poverty data from the 2000 census. Second, it estimated a propensity score at the block level to predict the probability that each block is offered the program. It then selected a representative sample of treatment "manzanas", matching them to a sample of "manzanas" from control areas with similar values of the propensity score. Obviously, certain area-level variables that would discriminate perfectly between treatment and control areas - e.g. the poverty density - were excluded from the propensity score.

Since the treatment and control sample are necessarily unbalanced in terms of these area level variables, the availability of a baseline survey, collected before the start of the program, is crucial, as it allows us to control for time-invariant unobservable differences. Besides having different proportions of poor households, treatment and control blocks differ also in the geographic distribution, as they are partly sampled from different states. We will come back to these issues when we discuss differential trends.

A further issue arises from the fact that the data are "choice-based", as they over-sample program participants. Thus, the fraction of eligible (i.e. poor) households participating into 
the program observed in our treatment sample is different from the true fraction of program participants. Fortunately, we can estimate the true proportion of participating households in each block from a different data set. ${ }^{2}$

The data used in this paper consist of the three waves of the urban evaluation sample Encelurb. The first wave was collected in 2002, after households had registered for Oportunidades, but before any payments had been made. The data come from 905 different blocks or "manzanas" in urban areas, 486 of which are treated, while the remaining 419 are not.

We had to drop from the analysis some households with insufficient information to calculate the poverty index, which in turn is used to classify them as potential beneficiaries or not. We explored the issue of non-random attrition in the overall sample and, in particular the possibility that the attrition rate differ significantly between treatment and control areas. We measured an overall attrition rate of about 8\% for poor households: we end up with data on 9192 households in 2004, from an initial sample of 9945 in 2002. Importantly, this attrition does not appear to be related to the area type. In 2004 we observe about $91 \%$ and $93 \%$ of the initial sample of households from treatment and control areas, respectively and we cannot reject the hypothesis that the attrition rate is the same in the two areas.

The information on consumption in the data set is remarkably detailed. We have information on the consumption of many types of food in the week prior to the interview, including the monetary value of consumption in kind as given by the respondents (either grown or received as pay or as a gift). We also know the value of expenditures for a long list of non-durable commodities: household-related goods, transport, personal care, education, children's and adult clothes, health, alcohol and tobacco, furniture, and entertainment. We transform all the figures to monthly equivalents. About $10 \%$ of the observations are missing for both food and non-food items, although the occurrence of missing observations does not seem to be related systemati-

\footnotetext{
${ }^{2}$ See Angelucci, Attanasio, and Shaw (2004) for further details.
} 
cally to wealth. ${ }^{3}$ After dropping observations with incomplete or missing responses, as well as trimming the top and bottom percentile of our food and non-food consumption measures, we are left with data on the change in consumption from its 2002 value for approximately 7320 and 6830 households in 2003 and 2004. The availability of pre-program data enables us to implement difference-in-difference estimators. The advantage of this class of estimators is that the required assumptions are on the change in the variable of interest, rather than on its level.

In Table 1 we report the means for non durable consumption divided in food and non-food. Food is the most important item in these households budgets, consistent with the fact that our sample includes very poor households, and the average share of food in total consumption is roughly $60 \%$. It is worth noting that control households exhibit significantly higher levels of consumption in 2002. In 2003, these differences have diminished considerably, especially for food, and in 2004 they have vanished altogether. Clearly the impact of Oportunidades has something to do with these results.

The level of total consumption is interesting because it gives an idea of how important the Oportunidades transfer is. As shown below, the average monthly transfers for treated households are 342 and 406 pesos in 2003 and 2004. This implies that the transfer was worth between $17 \%$ and $21 \%$ of overall 2002 consumption on average. For participant households who, as we will see, tend to be poorer than non-participant households, the grant might represent an even larger fraction of total consumption.

Interestingly, the average level of consumption is much lower than average monthly income (average consumption in 2002 is 1929 pesos in treatment areas and 2149 pesos in control areas, compared with average income of 3099 pesos and 3210 pesos). Such a large difference is unlikely to be consistent with the low level of savings (less than 100 pesos on average) and is even more

\footnotetext{
${ }^{3}$ We considered missing all food and non-food consumption observations with at least $30 \%$ missing data. That is, for food consumption we dropped observations that had more than 12 missing food consumption data (out of a total of 37 food categories). For non-food consumption, we dropped observations with more than 9 missing non-food consumption data (out of a total of 30 categories).
} 
puzzling if we consider the fact that consumption includes consumption in kind, while income does not. These numbers indicate either an over-estimation of income levels or, perhaps more likely (given that housing costs are excluded), an underestimate of consumption levels. The average transfers in 2003 and 2004 are respectively $11 \%$ and $13 \%$ of pre-program household income; thus, considered as a fraction of income, the program monetary incentives may not be very appealing. We will explore these issues later.

In Table 2, we report participation into the program and the average amounts received, according to the administrative data, in 2003 and 2004. It should be noticed that the annual averages mask a substantial amount of variation over the year, as the educational grants are typically not paid when the school is in recess, from July to September. Overall, $51.8 \%$ of eligible households participate to the program in 2003, and participation increases only by 2 percentage points in 2004. While one might have speculated that the low participation in the early stages of the program could have been due to poor information about the program existence, it seem unlikely that potential recipients would not know of it one year after its start. We will explore participation issues in Section 5.

\section{Identification of treatment effects}

We are interested in estimating the average effect of the treatment on the treated (ATT). However, given the low participation rate, the average intention to treat (AIT), is also of interest. In this section we outline our identification strategy.

We identify the ATT using a conditional version of the Local Average Treatment Effect (Angrist, Imbens, and Rubin 1996) and of the Bloom estimator (Bloom 1984, and Heckman 1996), where the availability of the treatment is not random, unlike in the other papers mentioned. Our data consist of a sample of poor households who live in two types of blocks: blocks where the program is offered to poor households $(Z=1)$ and blocks where the program is 
not implemented $(Z=0)$. We label these two types of geographic areas "program blocks" and "non-program blocks". We observe outcomes for households in both block types at time $t_{1}$, almost one year after the implementation of Oportunidades, and at time $t_{0}$, prior to the program start. The treatment consists of participation to Oportunidades.

Given these data, we define potential outcomes for household $i$ at time $t_{1}$ as $Y_{i t_{1}}(1)$ in the presence of the treatment, $D_{i t_{1}}=1$, and $Y_{i t_{1}}(0)$ without the treatment, $D_{i t_{1}}=0$. The relationship between potential and observed outcomes is $Y_{i t_{1}}=Y_{i t_{1}}(1) D_{i t_{1}}+Y_{i t_{1}}(0)\left(1-D_{i t_{1}}\right)$ and we observe only one potential outcome per household at each point in time. The variable $Z$ is our instrument. Define potential participation of a household $i$ at time $t_{1}$ as a function of the instrument: $D_{i t_{1}}(1)$ is potential participation where the household to live in a program block and $D_{i t_{1}}(0)$ is potential participation if living in non-program blocks. Participation is zero by definition in non-program blocks, as the program is not implemented there, i.e. $D_{i t_{1}}(0)=0$. Therefore, the relationship between observed and potential outcomes is $D_{i t_{1}}=$ $D_{i t_{1}}(1) Z_{i t_{1}}+D_{i t_{1}}(0)\left(1-Z_{i t_{1}}\right)=D_{i t_{1}}(1) Z_{i t_{1}}$.

The average treatment effect on the treated is:

$$
A T T=E\left[Y_{i t_{1}}(1)-Y_{i t_{1}}(0) \mid D_{i t_{1}}=1\right]
$$

Our key identification assumption is that, conditional on a set of observable characteristics measured in a pre-program time period $t=t_{0}, X_{i t_{0}}$, area of residence is independent of the potential treatment $D_{i t_{1}}(1)$ and $D_{i t_{1}}(0)$ and of the change in potential outcomes $\Delta Y_{i t}(1)=$ $Y(1)_{i t_{1}}-Y(1)_{i t_{0}}$ and $\Delta Y_{i t}(0)=Y(0)_{i t_{1}}-Y(0)_{i t_{0}}$, i.e. $Z_{i} \perp \Delta Y_{i t}(0), \Delta Y_{i t}(1), D_{i t_{1}}(0), D_{i t_{1}}(1) \mid X_{i t_{0}}$. That is, we allow residents of program and non-program blocks to have different levels of potential outcomes, but the differences are time-invariant, therefore they disappear by taking their first difference. ${ }^{4} Z$ has a positive causal effect on participation, that is $E\left[D_{i t_{1}}(1)\right]>0$.

\footnotetext{
${ }^{4}$ One can express potential outcomes as composed of two separate terms, one a function of $X$ and the other of $Z$, and this latter term is time invariant and constant across both potential outcomes: $Y(J)_{i t_{1}}=$
} 
Given our assumptions, we can define the ATT as

$$
A T T=E\left[Y_{i t_{1}}(1)-Y_{i t_{1}}(0) \mid D_{i t_{1}}(1)=1\right]
$$

From the above assumptions (and dropping the subscripts for expositional ease) it follows that

$$
\begin{aligned}
& E[\Delta Y \mid Z=1, X]-E[\Delta Y \mid Z=0, X]= \\
& E[\Delta Y(1) D(1)+\Delta Y(0)(1-D(1)) \mid Z=1, X]-E[\Delta Y(0) \mid Z=0, X]= \\
& E[\Delta Y(1)-\Delta Y(0) \mid D(1)=1, X] P(D(1)=1 \mid X)+E[\Delta Y(0) \mid X]-E[\Delta Y(0) \mid X]= \\
& E[Y(1)-Y(0) \mid D(1)=1, X] P(D=1 \mid Z=1, X)
\end{aligned}
$$

This notation implicitly assumes that potential outcomes for each subject are not affected by the treatment status of others. ${ }^{5}$ The last equality follows from footnote 4 and from the conditional independence of $Z$ from potential treatment, $P(D(1)=1 \mid X)=P(D(1)=1 \mid Z=$ $1, X)=P(D=1 \mid Z=1, X)$. Thus, the ATT for individuals with characteristics $X, A T T_{X}$, can be estimated as the ratio between the expected difference in observed outcomes in treatment and control areas and the observed probability of participation in treatment areas. We can express this as a function of the propensity score $P(X)=P(Z=1 \mid X)$ (Rosenbaum and Rubin 1983):

$$
A T T_{P(X)}=E[Y(1)-Y(0) \mid D(1)=1, P(X)]=\frac{E[\Delta Y \mid Z=1, P(X)]-E[\Delta Y \mid Z=0, P(X)]}{P(D=1 \mid Z=1, P(X))}
$$

If we further assume common support, i.e. $P(Z=1 \mid X)<1$, the $A T T$ is

$$
A T T=\int_{p} A T T_{P(X)=p} d F(p \mid D=1)
$$

With this approach one normally identifies the LATE, i.e. the average treatment effect for

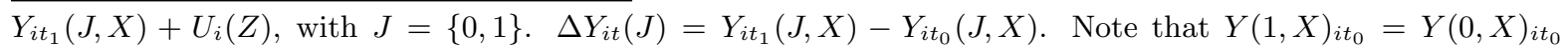
because the treatment has not started in $t=t_{0}$. Therefore, $Y(1)_{i t_{1}}-Y(0)_{i t_{1}}=Y(1, X)_{i t_{1}}-Y(0, X)_{i t_{1}}$ and $\Delta Y(1)_{i t}-\Delta Y(0)_{i t}=Y(1)_{i t_{1}}-Y(0)_{i t_{1}}$.

${ }^{5}$ This is the Stable Unit Treatment Value Assumption (SUTVA), formalized by Rubin (1980, 1986). 
the set of agents who are induced to participate in the program because of the instrument. In this particular case, though, our subjects consist only of "never-takers" $(D(1)=D(0)=0)$ and "takers" $(D(1)=1$ and $D(0)=0)$, as we have neither "always-takers" nor "defiers" (Angrist, Imbens, and Rubin 1996). Therefore, the subjects who are induced to participate in the program because they are offered the treatment are all the treated subjects (Angrist and Imbens 1994). ${ }^{6}$

Lastly, note that the numerator of $A T T_{P(X)}$ is the average intent to treat (AIT) for individuals with a given value of the propensity score $P(X)$. The AIT measures the effect of the program on eligible subjects, regardless of whether they participate in the program or not. Since often the policy maker has little influence on participation, the AIT is one relevant parameters for policy analysis. The AIT is also interesting for the following two reasons. First, because it provides a lower bound to the ATT under the assumption that the program effect on non participants in the treatment group is lower than its effect on participants. ${ }^{7}$ Second, because the identification of AIT requires less restrictive identification assumptions than that of ATT, as it effectively ignores the issue of what determines participation in the program. In this case the AIT is identified under the assumptions that the program has no effect in control areas, that the changes in potential consumption in treatment and control areas are independent of areas of residence, conditional on observables, and that there is full common support, $P(Z=1 \mid X)<1$.

Since only about half of the eligible households enrolled in the program and spillover effects to eligible non-participants are unlikely, we expect the AIT to be substantially smaller than the ATT. For example, if the program effect were homogeneous, the AIT would be half the

\footnotetext{
${ }^{6}$ There are other possible alternative approaches within the matching framework to the estimation of the ATT parameter. For instance, one could match eligible participants and non-participants in treatment areas, or participants and poor households from control areas. For more details on these alternative approaches, and why we believe our method of choice is more appropriate given the available data, see Angelucci and Attanasio (2006).

${ }^{7}$ The lower bound refers to a positive ATT, and further assumes that any effect of the treatment on eligible non-participants is smaller than the one on participants. See Hirano et al. (2000) for an application in which this latter assumption is violated.
} 
magnitude of the ATT in the absence of spillover effects.

\section{Are the identification assumptions credible?}

The identification of both the AIT and the ATT is based on three assumptions: SUTVA, conditional independence (CIA), and common support. In this section we discuss their plausibility.

We believe the SUTVA holds in these data. Angelucci and De Giorgi (2007) found that program recipients from rural areas share their transfer with ineligible households who live in the same village, increasing this latter group's consumption. However, for our identification assumption to hold we only require eligible participants to not share their transfer with eligible non-participants. It seems improbable that individuals who choose to not participate despite being eligible for the program, would later receive money or gifts from participants. Moreover the indirect effects in rural areas occur only about one year after the beginning of the program; therefore, it is unlikely that we could find such effects in urban areas in 2003, less than one year after the treatment started. For the 2004 data, if there are any positive indirect program effect to eligible non-participants, we will end up estimating an upper bound to the true $A T T .{ }^{8}$

The SUTVA is violated also if eligible participants share their transfer with members of their social network who live in non-program blocks and are sufficiently poor to have qualified for the program, had it been implemented in their city block. While in principle this is possible, in practice we expect that the likelihood of these latter households' being sampled is very small. In any case, if this were the case, (1) would estimate a lower bound to the ATT.

The CIA is a more problematic assumption in our data, first, because the areas where the program is implemented and the control areas have different poverty levels, and second because these areas are geographically unbalanced. While observing pre-program data enables us to control for time-invariant differences, it may be that areas with different poverty levels or from

\footnotetext{
${ }^{8}$ Spillover effects can also occur through their effect on prices and on the functioning of markets, among other ways. However, we believe this is unlikely to hold in our data.
} 
different local economies also have different growth rates. Heckman, Hichimura, and Todd (1997) show that sampling treatment and control subjects from different geographic areas may bias the estimates of the treatment effects, and that standard identification methods, such as difference-in-difference matching estimators, may not perform well in these circumstances.

Table 3 shows that the sampled areas are unbalanced at the geographic level: the proportion of treatment and control areas varies considerably by federal state; in Campeche, Morelos, and San Luis Potosi', there are treatment areas, but no control ones. This lack of balance at the geographic level may be problematic, if, for example, states have different local business cycles that affect the change in consumption. Indeed, there is substantial variation in GDP growth at the state level. The weighted average of the growth rates is significantly lower in program than in non-program blocks in 1999 and 2000, not statistically different in 2001, and significantly higher in 2002. ${ }^{9}$ Thus, program blocks experienced higher growth than non-program blocks at baseline. $^{10}$

To provide further evidence on the possibility of differential trends between treatment and control areas, we compare the pre-program trends of the three variables for which we have pre-2002 data. These are income, household head and spouse employment, which we observe since 1999. Ideally, we would like to see whether there are differential trends after the program is implemented, but a comparison of post-program observed outcomes is uninformative because the trend is likely affected by the program in treatment areas. Instead, we compare pre-program trends in observable variables. If there are differential trends in observable variables, it is possible that there may also be differential trends in unobservables, and that these differential trends may continue when the program starts.

For each of these three variables $(Y)$, we estimated two sets of regression using 1999 to 2002 data. One is a regression on different continuous time trends $(t)$ as second-order polynomials

\footnotetext{
${ }^{9}$ We estimated these effects weighting each state proportionally to the frequency of sampled households.

${ }^{10}$ The values of the differences (and standard errors) from 1999 to 20002 are respectively $-0.015(0.009),-0.017$ (0.004), - 0.005 (0.004), and 0.011 (0.003), clustering the standard errors at the state level.
} 
by block type. ${ }^{11}$ The other interacts a treatment area dummy $(T)$ with year dummies $(y)$ :

$$
\begin{aligned}
& Y_{i t}=\alpha_{0}+\alpha_{1} T_{i t}+\alpha_{2} t_{t}+\alpha_{3} t_{t}^{2}+\alpha_{4} T_{i t} t_{t}+\alpha_{5} T_{i t} t_{t}^{2}+u_{i t} \\
& Y_{i t}=\beta_{0}+\beta_{1} T_{i t}+\sum_{j=2000}^{2002} \beta_{2 j} y_{j}+\sum_{j=2000}^{2002} \beta_{3 j} T_{i t} y_{j}+u_{i t}
\end{aligned}
$$

A test of the joint significance of $\alpha_{4}+\alpha_{5}$ and tests of the significance of the $\beta_{3 j}$ coefficients are evidence of differential trends. We report these estimates in Table 4 . In addition, we show these trends in Figures 1, 2, and 3.

The evidence suggests that income has a significantly different trend in treatment and control areas; the trend in spouse employment also appears to be different (although we cannot reject the hypothesis of differential quadratic trends). Lastly, household heads' employment does not vary differentially across treatment and control areas. In both cases, the growth is higher in treatment areas especially between 2001 and 2002, as with the growth rates. While we can control for these observable differences, it is likely that treatment areas also have steeper trends in unobservable variables. Failure to control for these trends would result in upwardbiased estimates of the AIT and ATT, erroneously showing part of the fastest unobservable growth in treatment areas as a consequence of the program.

As a further robustness check, we tested for differential trends between quasi-poor households in treatment and control areas. These are households not sufficiently poor to be eligible for the program. Under the assumption of no program spillover effects, we compare both preand post-program trends for these households. If the quasi-poor and the poor are sufficiently similar, one could consider the evidence of differential trend among the quasi-poor as suggestive that such differences may occur among the poor too. While we failed to detect differences for income and household head employment, spouse employment in treatment areas is slower than

\footnotetext{
${ }^{11}$ We do not report specifications with linear trends because we could never reject the hypothesis that these trends differ by area type.
} 
in control areas between 1999 and 2001, and then grows faster between 2001 and $2003 .^{12}$

One possibility to address the issue of differential trends would be to include state dummies in the set of conditioning variables, assuming that differences in areas' geographic distribution are an important potential cause for different unobserved trends. Since the outcome variable is in first difference, adding state dummies allows for state-specific trends. However, this causes problems with the quality of the matches, as we will show below. An alternative possibility would be to condition on state GDP growth. Adding this variable to the set of covariates would account for differential trends between control and treatment areas, under the assumption that unobservable trends are a function of state growth rates.

To provide indirect evidence that state-specific growth accounts for some of the time-varying differences between treatment and control localities, we show that the differential growth rate in income disappears when we regress household income growth rate on GDP growth rate. As Table 5 shows, the coefficient of the treatment dummy is no longer significant once we add state GDP growth (column 2). Interestingly, conditioning on state dummies does not change the significance of the treatment coefficient (column 3). ${ }^{13}$ Note, however, that the absence of a significant difference of income growth once we condition on state GDP growth does not guarantee that the latter can successfully control for unobservable differences in trends.

This discussion leads to our third identification assumption, common support. Since treatment assignment is not randomized, the selection of variables for the propensity score is a crucial step in the estimation of treatment effects. This assumption differs from the previous two, since it is directly observable, and depends on the set of covariates we condition on. While all the applications that use matching methods have a trade off between conditioning on a large set of covariates that affect both participation and potential outcomes (making the CIA more

\footnotetext{
${ }^{12}$ Results available upon request.

${ }^{13}$ We repeated the same exercise for the first difference in income and employment for household head and spouse, and for the growth rate of head and spouse employment growth rate at the locality level, but these variables were never different between treatment and control areas, irrespective of whether we condition on GDP or not.
} 
credible) and having good support properties (i.e. a sufficiently large number of matches for each treated subject), in this case the dilemma is especially strong for the two aforementioned reasons: 1) different poverty rates and 2) different geographic location between the two block types. For this reason we present estimates of the propensity score that use different sets of covariates and discuss the validity of the CIA and common support assumptions under these alternative specifications.

Figure 4 shows the frequencies of the propensity scores. Some household-level variables, $X_{h}$, are common to all specifications. These are (using 2002 values, unless otherwise specified): household size dummies, number of children by age categories ( 0 to 5,6 to 12,13 to 15 , and 16 to 20) grouped according to their status (working, going to school, or neither), poverty index as a second-order polynomial (program eligibility is based on this index), income (as a second-order polynomial), savings (excluding domestic helpers and their relatives, and individuals whose relationship to other family members is missing) and debt, transitory shocks in 2002 such as death or illness of non-resident family member, job or business loss for resident family member, and whether the household suffered a natural disaster, doctor visits in the previous four weeks for children, head, and spouse (as three separate dummies); household head's and spouse's presence (including multiple heads), gender, literacy, education dummies (the categories are: no qualification, incomplete primary, complete primary, incomplete secondary, complete secondary, higher education), employment status in 2002 (employee or self-employed, the excluded category is unemployed), dummies for whether either head or spouse worked in 1999, 2000, and 2001, and income of head and partner in 2001, 2000, 1999 (as a linear term).

The top left panel of Figure 4, panel 1, also adds the following set of area-specific variables, $X_{a}$ : availability of primary, middle and secondary schools, and health centers (measured by number of facilities per resident), dummies for area size, poverty incidence (as a second-order polynomial), and number of households. All variables are measured at baseline, 2002. Moreover, 
we condition on dummies for receipt of welfare assistance in the previous 12 months, ownership of durable assets (car, truck, appliances, and home), and dwelling characteristics. ${ }^{14,15}$ The advantage of this propensity score is that it is based on a large set of household and area characteristics, making the CIA assumption quite believable. However, since area poverty level is one of the criteria to select treatment "manzanas" (the treated areas are the poorest ones), there is hardly any common support.

In panel 2 we drop all area variables and all the additional household-specific variables, keeping only the $X_{h}$ covariates. Note that we drop the additional household-specific variables because they are used to compute the household poverty level, which we condition on. ${ }^{16}$ Now there is complete common support. However, we suspect that in this way we may not be controlling for differential trends in treatment and control areas, making the CIA assumption questionable. Before discussing the other specifications, note that the comparison of panels 1 and 2 clearly highlights that, although the characteristics of households in program and nonprogram blocks appear to be fairly similar overall (i.e. the distribution of the propensity score in panel 2 does not differ substantially for control and treatment households), the areas they live in are not. There is nothing that can be done about this issue: it is an undesirable, yet unavoidable feature of this evaluation exercise.

The score in panel 3 has state dummies in addition to the variables used in panel 2 . In this way, we control for unobserved average area characteristics at the state level that might affect the change in consumption. We still have full common support, but the right tail of the distribution has a high density for households in program blocks, while it is very thin in non-program blocks. Consequently, the estimation in this part of the support will not be very

\footnotetext{
${ }^{14}$ We have information on receipt of each of the following programs: free tortilla, Liconsa or Conasupo milk, school breakfast, DIF, scholarship, transportation scholarhsip, INI, Probecat "alianza para el campo", "apoyo a la vivienda", Procampo, credit, Fonaes, PET, funds to micro, small, or medium entreprises, other state or municipal programs, and "seguro Popular".

${ }^{15}$ The dwelling characteristics are floor, roof, and walls materials, number of rooms, existence of water piping and of a bathroom.

${ }^{16}$ Dropping the household poverty level from the propensity score in panel 1 does not affect its support.
} 
precise. Panel 4 replaces state dummies with state annual GDP growth between 2000 and 2002; there is a substantial difference in the distribution of the propensity score between these latter two panels. Unlike in panel 2, now there is evidence of higher probability of participation in program blocks (which is what we expect since they do differ from non-program blocks), but there are fewer bad matches than in panel 3. Lastly, panels 5 and 6 use the covariates in 3 and 4, adding availability of primary, lower and upper secondary schools, and health centers, each measured by number of facilities per resident. We think that conditioning on these variables is potentially important because the availability of schools and medical centers may strongly influence both participation and outcome. However, in both cases the propensity score has a very thick right tail for treatment households, resulting in many bad matches. Although the common support assumption does not fail, we are concerned that estimates of treatment effects based on these propensity scores would not be very informative because we would end up comparing very different individuals.

In sum, adding area-level variables, which is the best approach in principle, creates zero common support. This is a reflection of the fact there is no overlap in aggregate poverty shares between treatment and control areas by construction. Adding state dummies may strike the right balance between satisfying the full common support condition, controlling for important determinants of both participation and outcome, and allowing for differences is area characteristics that might result in different unobservable trends for treatment and control localities. However, for about $50 \%$ of the treated households we have hardly any counterfactual. If we replace state dummies with state GDP growth between 2000 and 2002, we reduce the number of "bad" matches in the right tail of the distribution. While on one hand it is less clear whether we are properly controlling for differential trends, on the other hand the evidence from Table 5 shows that GDP growth, unlike state dummies, explains some of the differential variation in income growth by area type. 
Note that the area variables we omit from the computation of the propensity score are significant predictors of area of residence. However, our identification assumption is that, conditional on the variables we do include to estimate the propensity score, these omitted variables are unrelated to changes in potential outcomes.

\section{$5 \quad$ Program participation}

As mentioned in Section 2, the take up rate of Oportunidades in urban areas is around $50 \%$ even in 2004, more than one year after the program start. Understanding the reasons for such a low take-up rate has important policy implications. In particular, it would be interesting to understand by what extent the low participation rate is due to lack of information about the program's existence and features, uncertainty about eligibility (applicants find out whether

they are eligible for the program only after going to the application center), and inadequate monetary incentives. However, we do not have data on the intensity of program advertising, nor obvious sources of exogenous variation to identify these causal effects. Therefore, we will simply describe some characteristics of program participants, and discuss possible interpretations of these results. Although these correlates are not causal effects, they may provide useful insights about the process of self-selection in the program.

We estimate the probability of program participation for eligible households in treatment areas, $P(D=1 \mid X, Z=1)$ as a function of a large set of household and area characteristics, specifically the $X_{h}$ and $X_{a}$ covariates and the dummies for receipt of welfare assistance. Table 6 shows the effects of number of children by age categories varies according to their 2002 status (working, going to school, or neither). An increase in the number of children neither going to school nor working does not change the likelihood of being a program recipient, with the exception of children aged 0 to 5 ; the participation rate drops by $2.3 \%$ points for each extra child in this age group. This result may be due to the higher opportunity cost of leaving the 
house for mothers of very young children. On the other hand, having young children who go to school is associated with significantly higher probabilities of participation. The likelihood of being a program recipient is 3.6 and 5.5 percentage points higher for any child aged 6 to 12 and 13 to 15 who was attending school before the program started, while elder children's school attendance does not affect take-up rates. Lastly, child employment is correlated with lower take-up rates; the probability of participation is 6.5 and 4.0 percentage points lower for any child aged 13 to 15 and 16 to 20 who was working in 2002 . These results indicate that program participation is much higher among families whose kids would have gone to school irrespective of the program.

One possible explanation consistent with these findings is that the monetary incentives offered are probably not sufficient to induce some potential participants to move children from employment to schooling. To further investigate this issue, we looked at child employment. In program blocks, $16.2 \%$ and $43.7 \%$ of eligible respondents aged 13 to 15 , and 16 to 20 , respectively, had a job in 2002, with average monthly wages of 885 and 1451 pesos (and median wages of 800 and 1310 pesos). The monthly scholarship for program participants in 2003, however, was between 305 and 390 pesos for enrollment in lower secondary education (grades 7 to 9), and between 510 and 660 pesos for upper secondary enrollment (grades 10 to 12). These transfers amount to $270,345,451$, and 584 pesos at 2002 prices. Thus, the opportunity cost of switching from employment to schooling is much higher in urban than in rural areas, where the scholarships were between one half and two thirds of children's full time wages (Schultz 2004), and where the participation rates were much higher.

Table 7 reports the partial effects of consumption, poverty level, income, transitory shocks, and availability of schools and health centers. This table shows three things. First, poverty is a strong correlate of participation. According to the estimated effects, the household in the $75 \%$ percentile of the poverty distribution, which has a poverty level of 2.01 , is 16 percentage 
points or $69 \%$ more likely to be a program participant than the household in the $25 \%$ percentile, which has a poverty level of 1.04. Second, the concentration of health centers in the block is positively related to participation. The magnitude of the effect, however, is quite small, as the inter-quartile range in this case is only 2.8 percentage points. Third, participation is inversely related to both consumption and income, but not to temporary shocks.

One possible interpretation of these results is that the low participation rate depends on low expected benefits of the program for some eligible households. Only sufficiently poor households, with children who would have gone to school anyway, and with relatively easy access to health centers, enroll in Oportunidades. The low incentives to participate could be due to a mix of uncertainty about eligibility (e.g. for households who suspect they may not be poor enough), and inadequate monetary incentives (e.g. for children who work). It would be interesting to experiment with changes in the targeting rules. For example, one could identify some strong correlates of poverty that the potential recipients can easily recognize and offer the program to all households with that given set of characteristics. ${ }^{17}$

One alternative explanation for our results is that poorer households may have better access to information about the program. For example, since the program was advertised by driving around the treated neighborhoods, it is possible that households with a higher opportunity cost of time, such as less poor families, may have not been aware of its existence. However, while low participation in the early stages may be compatible with scarce information about the program's existence or its rules, the enrollment rate in 2004 is only marginally higher than the one in 2003. Moreover, although the intensity of advertising may be correlated with locality characteristics, explaining part of the observed positive correlation of poverty and availability of health centers with enrollment, information alone can hardly explain the different enrollment rates by age, school enrollment or employment status of potential scholarship beneficiaries.

\footnotetext{
${ }^{17}$ One simple approach would be geographic targeting, e.g. by offering the program to all the households who live within a certain postal code.
} 
To conclude, the available evidence suggests that both insufficient information and inadequate financial incentives may be responsible for the observed low participation rate to Oportunidades, and that further research to estimate the relative importance of these determinants is needed.

Irrespective of the relative importance of the incentive and information motives, participation appears to be correlated with permanent, rather than temporary factors. Poverty level and consumption are strongly significant; shocks such as loss of business and natural disasters do not have a statistical effect.

\section{Estimating the effect of Oportunidades on consumption}

In this section we present the estimates of the AIT and ATT effects of Oportunidades on consumption. We estimate the effect on food and non-food consumption separately. The former is most likely measured with higher precision since the survey questions about food consumption are asked referring to consumption in the previous week. The recall period for non-food consumption, on the other hand, is longer, ranging between one month and one year. We converted all data into monthly values.

We estimate the AIT by difference-in-difference local linear regression matching. To estimate the ATT, we take the estimated intent to treat (IT) parameter for each value of the propensity score $P(X)=P(Z=1 \mid X)$ and divide it by the probability of participation, $P(D=1 \mid Z=$ 1, $P(X)$ ), integrating over the density of the propensity score for the participants, as in equation (1). We estimate the propensity score by probit, and the standard errors of the AIT and ATT parameters using the block bootstrap, where the block is the locality (a locality is a set of "manzanas"), using 200 repetitions. ${ }^{18}$ We re-estimate the propensity score in each iteration. The chosen bandwidth is 0.6. However, the results are fairly stable when we use different values of the bandwidth; the estimated effects are unchanged with bandwidths that range

\footnotetext{
${ }^{18}$ We also experimented with 500 repetitions, but the standard errors did not differ substantially from the 200-repetition ones.
} 
between 0.25 and 0.8 , and increase by about $10 \%$ with smaller and larger bandwidths. We also tried estimating the treatment effects using the 5 nearest neighbors to identify the matched counterfactual; the point estimates were fairly similar to the local linear regression ones.

To show the sensitivity of the results to different conditioning sets, we estimate treatment effects using three different propensity scores. First, our preferred score, computed from household-level variables and GDP state growth to control for the possibility of state-specific unobserved trends without causing major support problems (panel 4 in Figure 4). Second, the propensity score with state dummies instead of GDP growth (panel 3 in Figure 4), in which case we end up matching about half the treated households with $5 \%$ of the control ones. Third, the propensity score computed using household characteristics only and no geographic variables (panel 2 in Figure 4). A comparison of the estimated treatment effect using these different scores will provide indirect evidence of the relevance of differential trends.

Tables 8 and 9 report the estimated treatment effects for consumption both in logs and levels. The advantage of estimating treatment effects in levels is that the estimates are directly comparable to the level of the grant. However, the presence of inflation, albeit common across the areas, affects the results as it has a multiplicative effect. We deal with issue by deflating the 2003 and 2004 consumption levels using average CPI values, likely measuring the true inflation with error. This is not a problem for the results in log since inflation cancels out from a difference in logs, so we do not have to worry about measurement error issues. ${ }^{19}$ In both tables we report the AIT and ATT effects of the program on consumption in 2003 and in 2004, that is one and two years after the beginning of Oportunidades.

According to the estimates from the first panel of Table 8, food consumption increases by $4.8 \%$ in 2003 and $7.2 \%$ in 2004 among eligible households in program blocks irrespective of participation (this is an estimate of the $A I T$ ), but these effects are imprecisely estimated

\footnotetext{
${ }^{19}$ There are a few families reporting zero non-food consumption, but these are only 11,34 , and 23 in the three data waves, so the fact that the values of log consumption for those households are set to missing is not a concern.
} 
and statistically insignificant at the conventional levels. The ATT are instead positive and significant in 2003 and 2004, and amount to 0.16 and 0.23. Non-food consumption does not change significantly; several point estimates are negative, and the estimates are generally very imprecise. In the second panel, where we substitute state GDP growth with state dummies for the computation of the propensity score, the results do not change much. The point estimates of the effects on food consumption are slightly larger, but still within the previous estimates' confidence intervals, and the effects of non-food consumption remain statistically insignificant. These results indicate that GDP growth might be doing a good job of capturing differential trends between treatment and control areas, although, relative to the figures in the second panel, the effects are not estimated with more precision. These results reveal that the program causes a large increase in food consumption.

In the bottom panel, when we completely eliminate state dummies or growth rates, the precision of the estimates improves considerably, reflecting the absence of support problems discussed in Section 4 for this particular case. However, the point estimates of the effects also change dramatically. In particular, the estimates of the ATT effects for food consumption increase by about 8 to 11 percentage points, compared with the point estimates from the top panel, becoming 0.24 and 0.34 in 2003 and 2004, respectively. Moreover, the estimated effects on non-food consumption become positive, significant, and quite large in 2004, with an AIT of 0.15 and an ATT of 0.39 , for instance.

We believe these latter sets of estimates are too large, consistent with the evidence from Section 4 suggesting a faster growth rate in treatment areas. Note also that the average treatment effect for eligible households in rural areas are respectively 0.13 and 0.15 for food and non-food log-consumption for the first 20 months since the program beginning. ${ }^{20}$

In Table 9, we repeat the exercise on the levels of food and non-food consumption. The

\footnotetext{
${ }^{20}$ Authors' calculations. Since the participation rate to the rural component of Oportunidades was roughly $97 \%$, the difference between this average treatment effect and the ATT is negligible.
} 
general picture is consistent with the one that emerges from Table 8. In particular, as before we find larger effects in 2004 than in 2003, insignificant estimates of the effect on non-food consumption, and larger (though more precise) point estimates when we fail to control for differential trends, as shown in the bottom panel of Table 9. Now we can assess the absolute magnitude of the program effects on consumption. Using the results from the top panel, the effects on food and non-food consumption are respectively 168 and -57 in 2003, and 282 and 141 in 2004 . These results suggest that part of the transfer is probably saved in 2003, as the estimate of the ATT is far lower than the average transfer of 316 pesos, while all the transfer is likely consumed in 2004, as monthly transfers for that year average 367 pesos. Overall, the average marginal propensity to consume for these two time periods is roughly $80 \%$. This is consistent with the evidence from rural areas, where $88 \%$ of the transfer was consumed in the first two and a half years since the program started (Gertler et al. 2006). The gradual increase in consumption over time is also consistent with the evidence from rural areas, where food consumption per adult equivalent among eligible households increased by 8,14 , and $17 \%$ about 6,12 , and 18 months after the beginning of the program..$^{21}$

Measuring the absolute value of the program effect on consumption is also interesting because we can indirectly check which propensity score is associated with plausible estimates of the program effects, and from there infer something about the validity of the identification assumptions. Obviously, neither the conditional independence assumption (CIA) nor the SUTVA are testable, but obtaining estimates that are grossly inconsistent with our priors is a first step to questioning their validity. In this particular case, since the the program take-up was so low, we do not think that program indirect effects on the eligible households in treatment areas who chose not to participate are likely, as we explained in Section 4. Thus, a comparison of the estimated effects may provide information on the whether the CIA holds for a given set of covariates. Comparing the estimated effects with and without controlling for state growth

\footnotetext{
${ }^{21}$ Authors' calculations.
} 
rates (the first and third panels of Table 9) shows that failing to control for differential trends produces bigger estimates of the treatment effects than when we add state GDP growth. This result is consistent with the evidence from Section 4, which suggested that areas where the program is offered started growing at a faster rate in 2002. Therefore, the estimated effects in panel 3 are probably upward biased, as they are partly reflecting the faster growth in treatment areas. Further, the estimated effects for 2004 in the bottom panel sum to a total consumption increase of 683 pesos. This is almost twice as much as the average transfer size for 2004, which is 367 pesos, thus providing additional indirect validation that these estimates are larger than the "true" effects. This result, together with our evidence of the possible existence of differential trends, suggests that the CIA is likely violated when we fail to control for these trends, and that the estimates on the first and second panel of the table are based on more realistic assumptions than the ones from the third panel.

\section{Conclusions}

In this paper we have looked at the effect of Oportunidades on consumption of food and nonfood items. There are several reasons why such an exercise is useful. First, consumption is interesting per se, as it is an obvious determinant of utility and, as such, might reflect individual perceptions about future opportunities and the like. Second, in a situation in which the absence of a randomization implies the use of different sets of assumptions, which might generate different results, the consumption results can be useful to assess indirectly the relative merits of different assumptions. This is possible because we have a strong prior on the range of estimates one should obtain given the level of the grant. Third, although not analyzed here, the study of different components of consumption can be important in assessing the effectiveness of the program in reaching the intended beneficiaries (children) and achieving its stated goals (investment in human capital). 
In the first part of the paper we analyzed two important problems for the current evaluation. First, we studied the trade off between conditioning on a set of variables that make the conditional independence assumption credible, and the lack of common support. More specifically, we believe that the presence of unobservable differential trends between treatment and control areas might be an issue in our data, as it would jeopardize the use of the difference-in-difference techniques used in this study. The second problem we studied is the low participation into the program.

We found our methodological worries, in particular the worry about differential trends, to be important. We suggest ways to control for them that can potentially be used in other applications. In particular, we find that trends seem to be different between treatment and control areas and tend to be more positive in treatment areas. However, we also argue that these trends can be reasonably captured by controlling for growth in state GDP.

We show that the low enrollment rate may be possibly caused by a low expected benefit of the program and that poverty is a very strong correlate of participation. However, we cannot rule out alternative explanations, such as low information about the program existence and features.

As for the effects of the program, we find that treated households tend to consume a large fraction of the grant, similarly to treated households in rural areas. Moreover, we find that a large fraction of the increase is in food. These results are not surprising, given that the households most likely to participate are the poorest ones; these families are both the least likely to save a part of the transfer to invest it, and the most likely to spend it to improve their nutrition. 


\section{References}

[1] Albarran, Pedro and Orazio Attanasio. 2003. "Limited Commitment and Crowding out of Private Transfers: Evidence from a Randomised Experiment." Economic Journal 113, no. 486:C77-C85.

[2] Angelucci, Manuela and Orazio Attanasio. 2006. "Estimating ATT effects with nonexperimental data and low compliance." Unpublished manuscript, Department of Economics, University College London.

[3] Angelucci, Manuela, Orazio Attanasio, and Jonathan Shaw. 2005. "The effect of Oportunidades on the level and composition of consumption in urban areas." In External Evaluation of the Impact of Oportunidades Program 2004: Education, eds. Henandez-Prado, B. and M. Henandez-Avila. Chapter 3, Vol. 4:105-52.

[4] Angelucci, Manuela and Giacomo De Giorgi. 2008. "Indirect Effects of an Aid Program: How do Cash Transfers Affect Non-Eligibles' Consumption?" The American Economic Review, forthcoming.

[5] Angrist, Joshua and Guido Imbens. 1994. "Identification and estimation of local average treatment effects." Econometrica 62, no. 2:467-75.

[6] Angrist, Joshua, Guido Imbens and Donald Rubin. 1996. "Identification of Causal Effects Using Instrumental Variables." Journal of the American Statistical Association 91, no. 434:444-55.

[7] Bloom, Howard. 1984. "Accounting for no-shows in experimental evaluation designs." Evaluation Review, 82, no. 2:225-46. 
[8] Gertler, Paul, Sebastian Martinez, and Marta Rubio-Codina. 2006. "Investing Cash Transfers to Raise Long Term Living Standards." World Bank Policy Research Working Paper No. 3994, World Bank, Washington, DC.

[9] Heckman, James. 1996. "Randomization and as intrumental variable." Review of Economics and Statistics 78, no. 2:336-41.

[10] Heckman, James, Hidehiko Hichimura, and Petra Todd. 1997. "Matching as an econometric evaluation estimator: Evidence from Evaluating a Job Training Program." Review of Economic Studies 64, no. 4:605-54.

[11] Hirano, Keisuke, Guido Imbens, Donald Rubin, and Xiao-Hua Zhou. 2000. "Assessing the Effect of an Influenza Vaccine in an Encouragement Design with Covariates." Biostatistics $1: 69-88$

[12] Hoddinot, John and Emmanuel Skoufias. 2003. "The impact of Progresa on food consumption." FCND Working Paper no. 150, International Food Policy Research Institute, Washington, DC.

[13] Imbens, Guido W. and Joshua D. Angrist. 1994. "Identification and estimation of local average treatment effects." Econometrica 62:467-76.

[14] Manski, Charles and Steven R. Lerman. 1977. "The Estimation of Choice Probabilities from Choice Based Samples." Econometrica 45, no. 8:1977-88.

[15] Rosenbaum, Paul R. and Donald B. Rubin. 1983. "The central role of the propensity score in observational studies for causal effects." Biometrika 70:41-55.

[16] Rubin, Donald B. 1980. "Discussion of Randomization Analysis of Experimental Data: The Fisher Randomization Test by D. Basu." Journal of the American Statistical Association. 75: 591-93. 
[17] Rubin, Donald B. 1986. "Which ifs have causal answers? Discussion of Hollands Statistics and causal inference." Journal of the American Statistical Association. 81:961-62.

[18] Schultz, Paul T. 2004. "School subsidies for the poor: evaluating the Mexican Progresa poverty program." Journal of Development Economics 74:199-250.

[19] Todd, Petra, Jorge Gallardo-Garcia, Jere Behrman, and Susan W. Parker. 2005. "Oportunidades Impact on Children and Youths Education in Urban Areas after One-year of Program Participation." In External Evaluation of the Impact of Oportunidades Program 2004: Education. Eds. Henandez-Prado, B. and M. Henandez-Avila, Chapter 3, Vol. $1: 167-227$. 
Table 1: Average monthly non-durable consumption

\begin{tabular}{|c|c|c|c|c|c|c|c|c|c|}
\hline & \multicolumn{3}{|c|}{2002} & \multicolumn{3}{|c|}{2003} & \multicolumn{3}{|c|}{2004} \\
\hline & C & $\mathrm{T}$ & pvalue & $\mathrm{C}$ & $\mathrm{T}$ & pvalue & C & $\mathrm{T}$ & pvalue \\
\hline total & 2291 & 1929 & 0.000 & $\begin{array}{c}2375 \\
(2101)\end{array}$ & $\begin{array}{c}2155 \\
(1826)\end{array}$ & 0.000 & $\begin{array}{c}2299 \\
(2034)\end{array}$ & $\begin{array}{c}2256 \\
(1911)\end{array}$ & 0.448 \\
\hline food & 1463 & 1280 & 0.001 & $\begin{array}{c}1357 \\
(1200)\end{array}$ & $\begin{array}{c}1329 \\
(1126)\end{array}$ & 0.114 & $\begin{array}{c}1368 \\
(1210)\end{array}$ & $\begin{array}{c}1389 \\
(1177)\end{array}$ & 0.375 \\
\hline non food & 828 & 649 & & $\begin{array}{c}999 \\
(884)\end{array}$ & $\begin{array}{c}825 \\
(699)\end{array}$ & 0.000 & $\begin{array}{c}930 \\
(823)\end{array}$ & $\begin{array}{c}866 \\
(733)\end{array}$ & 0.145 \\
\hline
\end{tabular}

$\mathrm{T}=$ Treatment group, $\mathrm{C}=$ Control group (as by locality). All the tables refer to poor households.

Poor households in $\mathrm{T}$ include eligible families not receiving the program. Values of consumption at 2002 prices in parentheses. 
Table 2: Participation into the Program and Amount of Transfer

\begin{tabular}{l|cc}
\hline \hline & 2003 & 2004 \\
\hline Participation (for the poor in treatment areas) & $51.8 \%$ & $53.9 \%$ \\
Average amount received (monthly) & 357 & 433 \\
& $(316)$ & $(367)$ \\
\hline
\end{tabular}

Transfer sizes at 2002 prices in parentheses. 
Table 3: Distribution of areas by state and average poverty level

\begin{tabular}{clcccccc}
\hline \hline $\begin{array}{c}\text { State } \\
\text { code }\end{array}$ & State name & Sample & \multicolumn{2}{c}{ Block Distribution (\%) } & \multicolumn{4}{c}{ GDP growth } \\
\hline 4 & Campeche & 1.70 & 0 & 100 & 0.081 & 0.047 & 0.011 \\
6 & Colima & 0.31 & 9 & 91 & 0.020 & -0.035 & 0.027 \\
7 & Chiapas & 15.28 & 23 & 77 & 0.040 & 0.014 & 0.030 \\
11 & Guanajuato & 1.71 & 58 & 42 & 0.074 & 0.009 & 0.049 \\
12 & Guerrero & 9.35 & 6 & 94 & 0.027 & 0.006 & -0.010 \\
13 & Hidalgo & 0.41 & 25 & 75 & 0.042 & -0.020 & -0.005 \\
15 & Mexico & 21.19 & 76 & 24 & 0.069 & 0.011 & -0.010 \\
16 & Michoacan & 4.14 & 14 & 86 & 0.012 & -0.013 & -0.007 \\
17 & Morelos & 4.31 & 0 & 100 & 0.049 & 0.035 & -0.009 \\
21 & Puebla & 7.36 & 71 & 29 & 0.043 & 0.011 & -0.012 \\
24 & San Luis Potosi & 0.03 & 0 & 100 & 0.061 & 0.001 & 0.008 \\
25 & Sinaloa & 0.51 & 98 & 2 & 0.083 & 0.019 & -0.012 \\
26 & Sonora & 2.50 & 94 & 6 & 0.073 & 0.008 & -0.045 \\
27 & Tabasco & 5.23 & 50 & 50 & 0.049 & 0.006 & -0.018 \\
28 & Tamaulipas & 2.44 & 23 & 77 & 0.075 & -0.025 & 0.036 \\
29 & Tlaxcala & 4.39 & 84 & 16 & 0.067 & 0.028 & -0.022 \\
30 & Veracruz & 19.15 & 2 & 98 & 0.040 & -0.004 & 0.002 \\
\hline \hline The frequencies are computed considering & \multicolumn{7}{c}{ only observations with non-missing income data in 20}
\end{tabular}

The frequencies are computed considering only observations with non-missing income data in 2003 . 
Table 4: Differences in pre-program trends

\begin{tabular}{|c|c|c|c|c|c|c|}
\hline & \multirow{2}{*}{\multicolumn{2}{|c|}{ Income }} & \multicolumn{4}{|c|}{ Employment } \\
\hline & & & \multicolumn{2}{|c|}{ Head } & \multicolumn{2}{|c|}{ Spouse } \\
\hline \multirow[t]{2}{*}{$T$} & 100.145 & -81.685 & 0.014 & 0.006 & 0.053 & 0.041 \\
\hline & [134.150] & [102.094] & {$[0.017]$} & {$[0.014]$} & {$[0.022]^{* *}$} & {$[0.014] * * *$} \\
\hline \multirow[t]{2}{*}{$T \times t$} & -212.018 & & -0.012 & & -0.014 & \\
\hline & {$[93.420]^{* *}$} & & {$[0.011]$} & & {$[0.016]$} & \\
\hline \multirow[t]{2}{*}{$T \times t^{2}$} & 45.649 & & 0.003 & & 0.004 & \\
\hline & {$[21.784]^{* *}$} & & {$[0.002]$} & & {$[0.004]$} & \\
\hline \multirow[t]{2}{*}{$T \times y_{2000}$} & & -15.092 & & -0.003 & & 0.01 \\
\hline & & {$[33.689]$} & & {$[0.005]$} & & {$[0.006]^{*}$} \\
\hline \multirow[t]{2}{*}{$T \times y_{2001}$} & & -87.373 & & -0.001 & & 0.001 \\
\hline & & {$[40.369]^{* *}$} & & {$[0.007]$} & & {$[0.007]$} \\
\hline \multirow{2}{*}{$T \times y_{2002}$} & & 77.848 & & 0.008 & & 0.03 \\
\hline & & [85.673] & & [0.008] & & {$[0.016]^{*}$} \\
\hline $\begin{array}{l}\text { Trend: test of joint } \\
\text { significance }\end{array}$ & {$[0.066]$} & & [0.279] & & {$[0.311]$} & \\
\hline
\end{tabular}

Standard errors [in brackets] clustered at the locality level. $* * * * * * *=$ significant at $10,5,1 \%$ level. P-value of the test of joint significance. 
Table 5: Differences in pre-program trends

\begin{tabular}{lccc}
\hline \hline & \multicolumn{3}{c}{ Income growth rate } \\
& 1 & 2 & 3 \\
\hline $\mathrm{T}$ & 0.034 & 0.027 & 0.057 \\
& {$[0.016]^{* *}$} & {$[0.017]$} & {$[0.018]^{* * *}$} \\
GDP growth & \multicolumn{3}{c}{-2.414} \\
& {$[0.310]^{* * *}$} \\
State fixed effects & No & No & Yes \\
\hline Observations & \multicolumn{4}{c}{23066} \\
\hline \hline
\end{tabular}

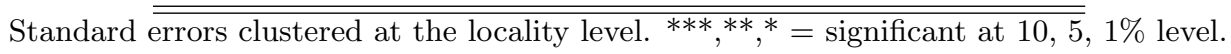


Table 6: Partial effects of an additional child on program participation, by children age and status.

\begin{tabular}{lccc}
\hline \hline & Neither school nor work & School & Work \\
\hline Age & -0.023 & 0.039 & - \\
$0-5$ & {$[0.011]^{* *}$} & {$[0.024]$} & \\
& -0.038 & 0.036 & - \\
$6-12$ & {$[0.025]$} & {$[0.010]^{* * *}$} & \\
& -0.024 & 0.055 & -0.065 \\
$13-15$ & {$[0.029]$} & {$[0.016]^{* * *}$} & {$[0.037]^{*}$} \\
& -0.005 & -0.002 & -0.040 \\
$16-20$ & {$[0.026]$} & {$[0.034]$} & {$[0.020]^{* *}$} \\
& \multicolumn{3}{c}{} \\
Obs. & 5451 & \\
\hline
\end{tabular}

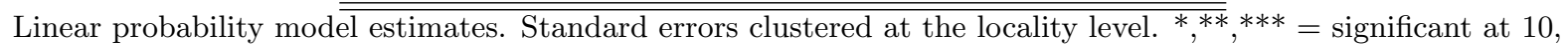
$5,1 \%$ level. 
Table 7: Selected determinants of program participation: partial effects and means.

\begin{tabular}{|c|c|c|}
\hline & $\begin{array}{c}\mathrm{LPM} \\
(1)\end{array}$ & $\begin{array}{c}\text { Mean } \\
(2)\end{array}$ \\
\hline \multirow[t]{2}{*}{ food consumption ${ }^{(a)}$} & -0.004 & 1.280 \\
\hline & {$[0.001]^{* * *}$} & {$[3.655]$} \\
\hline \multirow[t]{2}{*}{ nonfoood consumption $^{(a)}$} & -0.067 & 0.649 \\
\hline & {$[0.019]^{* * *}$} & {$[0.593]$} \\
\hline \multirow[t]{2}{*}{ poverty } & 0.275 & 1.614 \\
\hline & {$[0.047]^{* * *}$} & {$[0.727]$} \\
\hline \multirow[t]{2}{*}{ poverty $^{2}$} & -0.039 & \\
\hline & {$[0.011]^{* * *}$} & \\
\hline \multirow[t]{2}{*}{ primary school ${ }^{(b)}$} & 1.707 & 0.002 \\
\hline & {$[17.246]$} & {$[0.001]$} \\
\hline \multirow[t]{2}{*}{ lower secondary ${ }^{(b)}$} & -68.157 & 0.0006 \\
\hline & {$[75.594]$} & {$[0.0004]$} \\
\hline \multirow[t]{2}{*}{ upper secondary ${ }^{(b)}$} & 1.941 & 0.0005 \\
\hline & {$[73.614]$} & {$[0.0003]$} \\
\hline \multirow[t]{2}{*}{ health centers $^{(b)}$} & 142.023 & 0.0003 \\
\hline & {$[85.073]^{*}$} & {$[0.0003]$} \\
\hline \multirow[t]{2}{*}{ income } & -0.008 & 3.099 \\
\hline & {$[0.003]^{* * *}$} & {$[5.610]$} \\
\hline \multirow[t]{2}{*}{ income $^{2(a)}$} & 0.00003 & \\
\hline & {$[0.000009]^{* * *}$} & \\
\hline \multirow[t]{2}{*}{ death } & 0.027 & 0.126 \\
\hline & {$[0.028]$} & {$[0.332]$} \\
\hline \multirow[t]{2}{*}{ unemployment } & 0.026 & 0.172 \\
\hline & {$[0.020]$} & {$[0.377]$} \\
\hline \multirow[t]{2}{*}{ loss of business } & 0.171 & 0.005 \\
\hline & {$[0.126]$} & [0.069] \\
\hline \multirow[t]{2}{*}{ natural disaster } & -0.001 & 0.045 \\
\hline & {$[0.034]$} & {$[0.207]$} \\
\hline Obs. & 5451 & \\
\hline
\end{tabular}

${ }^{(a)}$ : consumption and income are in thousand pesos. ${ }^{(b)}$ : number of schools or centers per household in the locality. Linear probability model estimates in column (1). Standard errors clustered at the locality level. ${ }^{* * *},{ }^{* * *}=$ significant at $10,5,1 \%$ level. Sample averages and standard deviations in column (2). 
Table 8: Treatment effect estimates for food and non-food consumption in logs using different propensity scores.

\begin{tabular}{ccccc}
\hline \hline & \multicolumn{3}{c}{ food } & \multicolumn{2}{c}{ nonfood } \\
& 2003 & 2004 & 2003 & 2004 \\
\hline \multirow{4}{*}{ AIT } & 0.048 & 0.072 & -0.161 & -0.021 \\
& {$[0.042]$} & {$[0.046]$} & {$[0.117]$} & {$[0.123]$} \\
ATT & 0.164 & 0.231 & -0.205 & 0.086 \\
& {$[0.082]^{* *}$} & {$[0.095]^{* *}$} & {$[0.262]$} & {$[0.227]$} \\
& State dummies, no geographic variables \\
AIT & 0.072 & 0.089 & -0.092 & -0.004 \\
& {$[0.051]$} & {$[0.053]^{*}$} & {$[0.117]$} & {$[0.141]$} \\
ATT & 0.208 & 0.265 & -0.085 & -0.118 \\
& {$[0.102]^{* *}$} & {$[0.109]^{* *}$} & {$[0.227]$} & {$[0.261]$} \\
& No state dummies and & no geographic variables \\
AIT & 0.089 & 0.137 & 0.019 & 0.151 \\
& {$[0.025]^{* * *}$} & {$[0.023]^{* * *}$} & {$[0.056]$} & {$[0.078]^{*}$} \\
ATT & 0.242 & 0.349 & 0.120 & 0.394 \\
& {$[0.054]^{* * *}$} & {$[0.057]^{* * *}$} & {$[0.117]$} & {$[0.156]^{* * *}$} \\
\hline Obs. & 7320 & 6826 & 7295 & 6801 \\
\hline
\end{tabular}

Standard errors computed using block-bootstrap with 200 repetitions. The block is the locality. ${ }^{*}, * *, * * *=$ significant at 10, 5, $1 \%$ level. 
Table 9: Treatment effect estimates for food and non-food consumption in levels using different propensity scores.

\begin{tabular}{ccccc}
\hline \hline & \multicolumn{3}{c}{ food } & \multicolumn{2}{c}{ nonfood } \\
& 2003 & 2004 & 2003 & 2004 \\
\hline \multirow{4}{*}{ State gdp growth, no geographic variables } \\
AIT & 44.06 & 86.12 & -58.31 & 31.21 \\
& {$[57.00]$} & {$[46.20]^{*}$} & {$[64.82]$} & {$[57.96]$} \\
ATT & 168.54 & 282.85 & -57.00 & 141.57 \\
& {$[108.87]^{*}$} & {$[95.82]^{* * *}$} & {$[120.88]$} & {$[110.58]$} \\
& State dummies, no geographic variables \\
AIT & 75.62 & 86.33 & -26.78 & 29.30 \\
& {$[62.19]$} & {$[54.43]$} & {$[59.03]$} & {$[67.32]$} \\
ATT & 228.28 & 287.41 & 1.84 & 139.52 \\
& {$[123.28]^{*}$} & {$[114.18]^{* * *}$} & {$[113.86]$} & {$[127.85]$} \\
& No state dummies and no geographic variables \\
AIT & 102.15 & 150.28 & 22.34 & 110.22 \\
& {$[31.03]^{* * *}$} & {$[27.46]^{* * *}$} & {$[29.37]$} & {$[39.49]^{* * *}$} \\
ATT & 279.58 & 400.66 & 92.90 & 282.87 \\
& {$[65.59]^{* * *}$} & {$[65.88]^{* * *}$} & {$[60.40]$} & {$[81.63]^{* * *}$} \\
\hline Obs. & 7322 & 6824 & 7320 & 6829 \\
\hline
\end{tabular}

Standard errors computed using block-bootstrap with 200 repetitions. The block is the locality. ${ }^{*}, * *, * * *=$ significant at $10,5,1 \%$ level. 


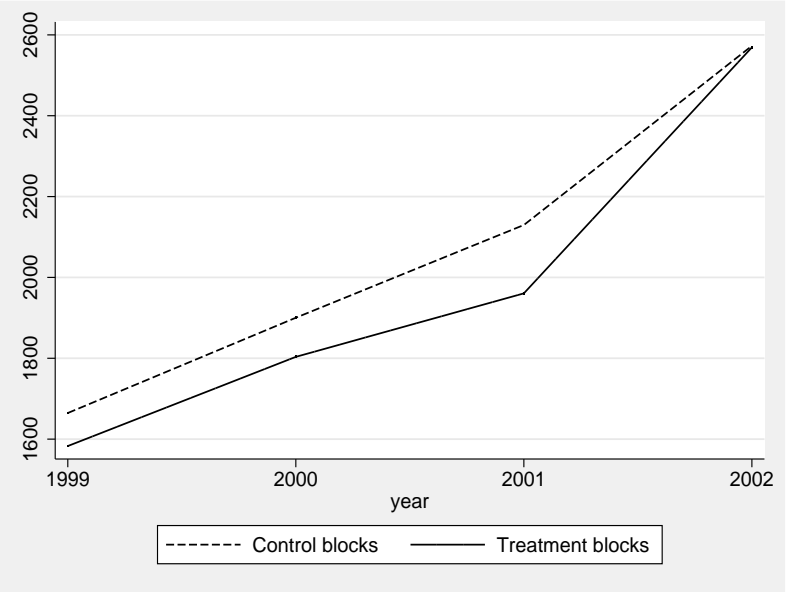

Figure 1: Average income for poor households in treatment and control areas, 1999-2002.

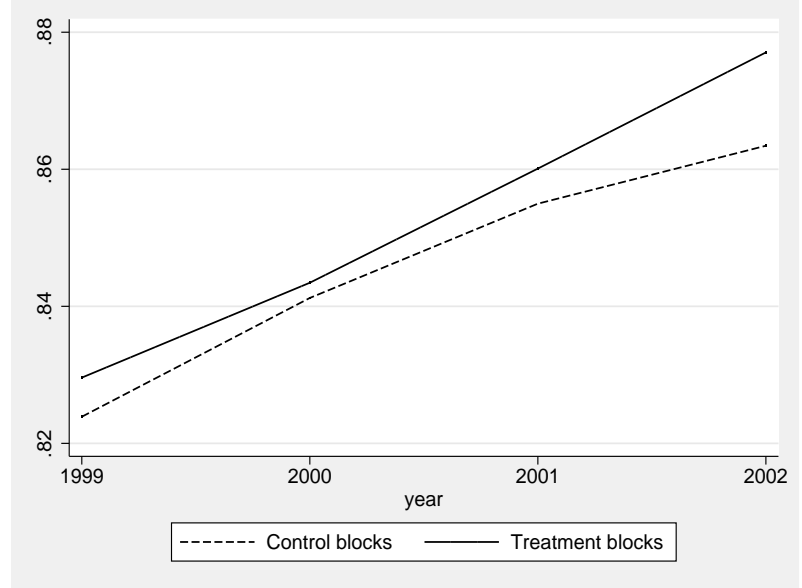

Figure 2: Average employment of household heads for poor households in treatment and control areas, 1999-2002.

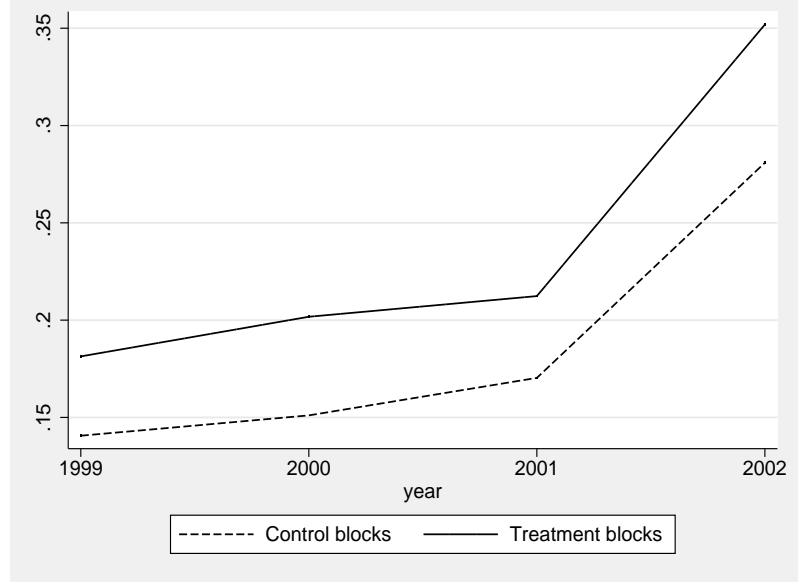

Figure 3: Average spouse employment for poor households in treatment and control areas, 1999-2002. 


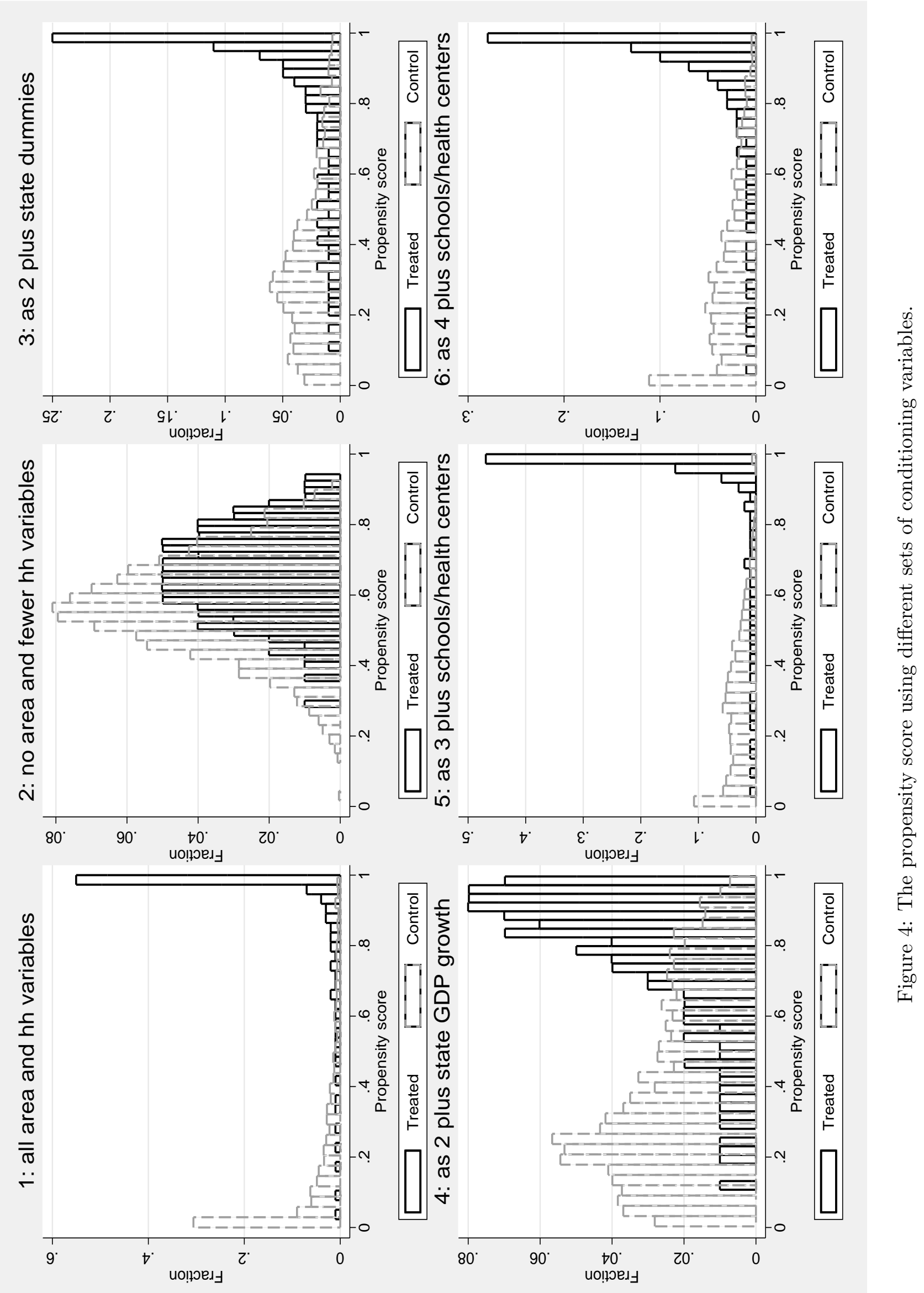

